\title{
Contingentism about Individuals and Higher-Order Necessitism *
}

\author{
Manuel PÉREZ OTERO
}

Received: 29.10.2012

Final version: 05.02.2013

BIBLID [0495-4548 (2013) 28: 78; pp. 393-406]

DOI: $10.1387 /$ theoria.6882

ABSTRACT: Necessitism about individuals claims that necessarily every individual necessarily exists. An analogous necessitist thesis attributes necessary existence to properties and relations. Both theses have been defended by Williamson. Furthermore, Williamson specifically argues against the hybrid conjunction of first-order contingentism (the negation of necessitism about individuals) and higher-order necessitism; a combination that would bring about additional drawbacks. I work out a defence of the hybrid combination, including some replies to Williamson's additional objections. Considerations of ontological parsimony and pretheoretical intuitions favour the hybrid view over necessitism at all orders (which Williamson mainly defends by invoking considerations of simplicity).

Keywords: Williamson; ontological parsimony; pre-theoretical intuitions; Barcan Formula; simplicity; possible worlds semantics; modal logic; contingentism; necessitism.

RESUMEN: Según el necesitismo sobre los individuos, necesariamente todo individuo necesariamente existe. Una tesis necesitista análoga atribuye existencia necesaria a propiedades y relaciones. Ambas tesis han sido defendidas por Williamson. Además, Williamson argumenta específicamente contra la conjunción híbrida de contingentismo de primer orden (la negación del necesitismo sobre los individuos) combinado con necesitismo de orden superior; una combinación que acarrearía problemas adicionales. En este artículo desarrollo una defensa de esa combinación híbrida, incluyendo algunas réplicas a tales objeciones adicionales de Williamson. Consideraciones de parsimonia ontológica e intuiciones pre-teóricas favorecen la concepción híbrida frente al necesitismo en todos los órdenes (defendido por Williamson basándose, principalmente, en consideraciones de simplicidad).

Palabras clave: Williamson; parsimonia ontológica; intuiciones pre-teóricas; Fórmula Barcan; simplicidad; semántica de mundos posibles; lógica modal; contingentismo; necesitismo.

\section{Introduction}

A certain metaphysical modal thesis establishes that necessarily every individual necessarily exists. Let's call this claim necessitism about individuals, or first-order necessitism. An analogous necessitist thesis would attribute necessary existence to second order entities,

* I have presented the contents of this paper at an invited lecture at the University of Buenos Aires, in the GAF group, in September of 2012. The subject has also been discussed at two meetings of the LOGOS group, at the University of Barcelona: a reading group in January of 2010 and a seminar with Timothy Williamson in January of 2012. I am indebted to the people who attended those events, and to others who have read previous written versions of the ideas contained in this work. Thanks particularly to Eduardo Barrio, Genoveva Martí, Gabriel Uzquiano, Tim Williamson and an anonymous referee of this journal. Financial Support: Program CONSOLIDER-INGENIO 2010, "Philosophy of Perspectival Thoughts and Facts" (CSD2009-00056), MICINN (Spanish Government). Project "Knowledge, Reference and Realism" (FFI2011-29560-C02-01), MICINN (Spanish Government). Consolidated and Funded Research Group LOGOS (2009 SGR 1077), AGAUR (Catalan Government). 
properties of individuals and relations between individuals. If-for the sake of simplicity - we restrict our concern (regarding second-order entities) to properties (as I will do in this paper), necessitism about properties (second-order necessitism) says that necessarily every property necessarily exists. The negation of necessitism can be named contingentism. So, there is a contingentist view about individuals and a contingentist view about properties. In fact, the contingentism/necessitism dispute is reproduced at every level (for higher-order properties and relations as well).

The terminology is borrowed from Timothy Williamson's work, where we find a vigorous and thorough defence of necessitism at all orders (cf. Williamson 1998, 2000, 2002, 2010, 2013). He has offered - in my view - the most powerful arguments we can find in the literature for each of the two main theses: first-order necessitism and higher-order necessitism (necessitism about properties and relations of any order). Furthermore, Williamson also argues specifically against the conjunction of first-order contingentism and higher-order necessitism; a combination that would bring about additional drawbacks (cf. Williamson 2013, ch. 6). My main aim in this article is to defend such a combination (contingentism about individuals and higher-order necessitism). Before doing so, I will briefly sketch the main pieces of evidence provided by Williamson against first-order contingentism, as well as my responses (Sections 3 and 4). Then Williamson's evidence for higher-order necessitism is described (Section 5); here I tentatively accept his view on this, so that my preferred position is to endorse higher-order necessitism but to reject necessitism about individuals. Williamson's criticisms to this conjunction and my responses to his worries are laid out in Sections 6 and 7. Before all this, in the next section, I devote some space to introducing the debate, including a few remarks about how the contingentism/necessitism dispute connects with (different versions of) the Barcan Formula, and a first appraisal of what our pre-theoretical intuitive judgments about these issues are. As we progress through the paper it will become clear that we find in Williamson's texts what can be appropriately described as new, completely original evidence for a very old metaphysical hypothesis that I will call modal metaphysical atomism, as presented in the final section: Section 7.

\section{Barcan Formulas and necessitism}

First of all, let me offer formal versions of the main necessitist theses which I am going to discuss here. In the absence of specific predicates for existence, first-order necessitism and second-order necessitism (restricted to monadic properties) can be formalized, respectively, as Nec1 and Nec2:

(Nec1) $\quad \square \forall x \square \exists y(x=y)$

(Nec2) $\quad \square \forall X \square \exists Y(X=Y)$

I will use 'Nec1' to refer indifferently to both the metaphysical claim (necessitism about individuals) and to this formal version of it, since the discussion will not depend on subtleties regarding how well the former is captured by the latter. Likewise with respect to 'Nec2'. 
From Nec1, each instance of the Barcan Formula follows. Probably the most common version of the Barcan Formula is BF1:

$$
\diamond \exists x F(x) \rightarrow \exists x \diamond F(x)^{1}
$$

BF1 says that if there can be an individual $x$ that is $F$, then there is an individual $x$ that is F. In terms of possible worlds, it establishes (assuming some other simplifications that I will not question here) that each possible individual (the inhabitant of any possible world) exists in the actual world. This is a clear consequence of Nec1, because Nec1 entails that all possible worlds have the same domain. ${ }^{2}$

For second-order, we have the following version of the Barcan Formula:

$$
\diamond \exists X A(X) \rightarrow \exists X \diamond A(X)
$$

It establishes that if there can be a property $X$ that is $A$, then there is a property $X$ that is $A$. BF2 is a logical consequence of $\mathrm{Nec} 2$, just as $\mathrm{BF} 1$ is a logical consequence of Nec1.

In his brilliant and detailed exposition of the subject, Williamson recommends as the best option for the defender of BF1 that it be accommodated within a general conception where Nec1 also holds (even if BF1 is compatible with the negation of Nec1). The same recommendation ensues with respect to BF2 vis-à-vis Nec2. I am very sympathetic to a great deal of Williamson's terminological and methodological considerations and suggestions. That includes his relatively common treatment of Nec1 and BF1 (and his similar treatment of Nec2 and BF2). As far as I am concerned, I also treat Nec1 and BF1 in this shared manner; my objections against them apply equally to both. In the same way, I will accept (for the reasons Williamson provides; cf. Section 5 below) not only BF2 but also Nec2.

Now, it is time to start our evaluation of Nec1 and BF1. There is a strong prima facie objection to BF1 (which therefore also counts against Nec1). Depending on how that objection is confronted, a second objection may emerge too. The first objection is that some instances of the formula are pre-theoretically very counterintuitive. We may invoke one of the most common examples, sentence (1):

(1) $\diamond \exists x$ (Wittgenstein fathered $x) \rightarrow \exists x \diamond$ (Wittgenstein fathered $x$ )

Leaving aside radical scepticism about modality, we can easily accept the truth of the antecedent of (1). From BF1 and the antecedent of (1), we can derive its consequent. But, as a matter of fact, Wittgenstein had no children. So, if BF1 is valid, some actual entity that is not a child of Wittgenstein could have been a child of Wittgenstein. In my view, this result contradicts some very firmly rooted intuitions about ontology and modality. No human being (child of other parents) seems to be a candidate

\footnotetext{
${ }^{1}$ The formula has had this name, since the mid 1950s, because Ruth Barcan Marcus had proposed an almost identical formula in the previous decade, in her pioneering writings on quantified modal logic. She later defended the formula proposing a substitutional reading of the quantifiers, different from the standard objectual reading that I will assume in this work (cf. Marcus 1962). An evaluation of her substitutional theory of quantification would deviate us from the main purpose in this article.

${ }^{2}$ I will not deal with issues about accessibility relations between possible worlds. For the sake of simplicity, I will treat all possible worlds as accessible to each other.
} 
entity. Nor does any other kind of living being, let alone some other individual belonging to one of the ontological categories we are familiar with (rocks, tables, planets, electrons, numbers, etc.).

The defender of BF1 has two main options. She may defy these intuitions and propose that one of those familiar entities (a living being, or an artefact, or another kind of physical object, or an abstract entity) could have been a child of Wittgenstein (even if it actually is not). A more promising strategy (followed by Williamson and some other philosophers) is to postulate a new ontological category of entities that was unknown until now. For Williamson, such would-be children of Wittgenstein are possibly concrete entities: non-concrete entities which, unlike abstract entities, could be concrete (that is, in some other possible worlds they are concrete). (Williamson's ontological theory is close to that of Linsky and Zalta 1994.) The pre-theoretical intuition that is violated by this strategy is not exactly that none of these entities (non-concrete but possibly concrete entities) could be a child of Wittgenstein, but that there are no such entities. Of course, abstract theoretical inquiry may require us to postulate their existence; but right now I am describing some of our pre-theoretical intellectual seemings; and they include the prima facie rejection of non-concrete but possibly concrete entities.

A second objection can be raised against the strategy followed by Williamson: considerations of ontological parsimony speak against it. And they do so in two senses: the strategy proposes the actual existence of a lot of new things (things we did not think existed); and it also proposes the actual existence of a new ontological category of beings (non-concrete but possibly concrete beings).

As far as I can see, nothing in Williamson's view prevents him from admitting such prima facie double evidence against BF1 (it goes against first intuitions; and when supported by the postulation of new entities, it is ontologically uneconomical). On the contrary, we can find claims such as: "Any philosophical assessment of BF [...] must start by acknowledging that there seem to be compelling counterexamples to [it]" (Williamson 2010, Section 1). But pre-theoretical intuitions and very general criteria of ontological parsimony are far from being enough to settle metaphysical issues such as this. I completely agree with Williamson that theoretical inquiry is needed if we are to reach a wiser view: "Only theoretical inquiry can properly address the question" (Williamson 2013, ch. 1). So let us have a look, in the following sections, at what theoretical inquiry could be invoked to counter such double evidence against Williamson's defence of Nec1.

\section{The evidence against first-order contingentism: philosophical interpretations of possible worlds semantics}

For reasons of space, I will confine myself to what I take to be the two most prominent arguments for BF1 found in Williamson's works. The discussion of the first, in this section, will be just a brief and very schematic sketch of the issue (as anything more detailed would require much more attention; I discuss it extensively in Pérez Otero 2009, 2010). It concerns the philosophical interpretation of possible worlds se- 
mantics. The second argument addresses questions of simplicity in our election of a logic theory, and I will deal with it in the next section.

We must, first, restrict ourselves to those models of possible worlds semantics (PWS, henceforth) that could be considered as intended models. The existence of counter-models to BF1 in PWS is irrelevant to the contingentism/necessitism dispute, which concerns the intended interpretation of instances of BF1 (I agree with Williamson on this). Now, according to Williamson, PWS must be taken at face value, in a realist sprit. He thinks that such a realist stance involves reading PWS as a full, complete theory of meaning of our modal natural languages. That, in its turn, would commit us as to accepting, as the best philosophical conception of modality within which to accommodate PWS, one in which the domain of the actual world must be identified with the domain of what in PWS is sometimes called "the actual world" of any of the intended models taken as realist models of our natural language. (Williamson would say that there is just one intended model.)

According to some views opposed by Williamson, such "actual worlds" of models of PWS—we can call them @, as it is usual—are just representational set-theoretic entities. Their domain - their defenders would say — is not identical to the domain of the actual world. If we identify @'s domain with the domain of the actual world, then (I think Williamson is right on this) each instance of BF1 is true, since any individual belonging to the domain of a possible world w, but supposedly not in @'s domain (a would-be child of Wittgenstein, for instance), must be quantified over when we formulate-in the meta-language- the semantics clauses of PWS. So, any of those individuals must exist, i.e. must belong to the domain of the actual world. If such a domain coincides with@'s domain, then@ also contains the individual. (Cf. Williamson 1998; 2013, ch. 3 and 4.)

Williamson is well aware of the alternative I have mentioned (that the actual world and @ do not have the same domain). He alludes to it:

The domain D(@) of the actual world@ of such a structure would somehow represent or go proxy for everything without containing everything, thereby leaving some objects over to belong to the domains only of other worlds and thereby falsify some instances of BF1, if required. (Williamson 2013, section 3.6. I have made some very minor terminological adjustments.)

However, he rules out this view as instrumentalist and thereby incompatible with the realist perspective we should adopt towards PWS; a realist perspective that - he thinks-requires us to take PWS as a complete theory of meaning of modal sentences. Some traits of the meaning of some sentences (for instance, its de re character, the singular representational content) would not be appropriately captured if the intended models, the "actual world", @, in them and the individuals in @'s domain are merely representational artefacts.

What Williamson calls an "instrumentalist" interpretation of PWS is-I think-the right view. ${ }^{3}$ A contingentist is not committed to accepting (Williamson's work proba-

3 The point at stake does not depend on whether the alternative criticized by Williamson deserves the tag 'instrumentalism' or not. But I reject the tag (although most of Williamson's terminological decisions seem accurate to me). The alternative I propose is a realist view of strict PWS, even if it may be considered a non-realistic conception of possible worlds and their "inhabitants" under the philosophical 
bly shows that she should not accept) that PWS is the (full, complete) semantic theory for modal natural languages. The function of models (in PWS) is not to model all traits that are relevant to the semantics. I conceive of PWS as an important part, but only a proper part, of a completely appropriate semantic theory of meaning for modal natural languages. For instance, it may in particular be demanding too much of PWS to require that it accounts for the fact that sentences containing the name 'Socrates' (in use) concern, de re, Socrates. What determines facts such as this are the kind of factors which also determine which models should count as intended models and these factors are external to strict PWS: they would be part of the conceptual foundations of PWS (as I have called them elsewhere; cf. Pérez Otero 2010).

To put it in Williamson's own words:

Of course, we can endow a model with a rich actuality-involving representational significance from outside, for instance by explaining independently of the model how to read the non-logical atomic expressions of the language. But that is to relegate the model to a largely instrumental role. It merely determines which sentences are represented as true; what they mean is determined elsewhere. (Williamson 2013, section 4.9)

I endorse with some qualifications this strategy (committed with the idea of enriching the model "from outside") that Williamson rejects. The dichotomy telling-whichsentences-are-true/telling-what-they-mean is potentially misleading. PWS captures part of what sentences mean. And PWS's apparatus allows us to formulate (even if PWS by itself does not decide) some other traits of meaning in a precise way. For instance, regarding "singular" representational content: the intuition that sentences containing the name 'Socrates' concern, de re, the singular thing Socrates is partially captured by the requirement that proper names have the same denotation in all possible worlds (in any "intended" model). I recognize that the de re intuition goes beyond that. But PWS was originally conceived mainly as a logic theory, and this is also the case in the context of Williamson's texts. It is plausible to sustain that the remaining part of the intuition goes beyond the scope of modal logic. 4

\section{The evidence against first-order contingentism: criteria of simplicity}

Let us now consider the other prominent argument for BF1 in Williamson's work, which concerns the criteria of simplicity in the election of a logic theory. Williamson describes the costs of renouncing to Nec1 in our preferred logic theory. In a nutshell, the cost that contingentists have to pay for denying Nec1 is to "either adopt free logic even for the non-modal fragment of their language or restrict necessitation (perhaps both)" (Williamson 2013, Section 2.2). Systems of free logic are mainly motivated by

presupposition that "possible worlds" should be understood, by default, in some ultra-realist way, close to Lewis' or to Williamson's own view about such “inhabitants". PWS cannot be identified with any particular philosophical theory of "possible worlds". Cf. Section 4 of my Pérez Otero 2010, specially note 8 .

${ }^{4}$ I fully develop this contingentist interpretation of PWS in Pérez Otero $(2009,2010)$. Some of the main key ideas come from Pérez Otero (1996, 1999). Related views can be found in Menzel (1990), Rosen (1990) and Chihara (1998). For some recent statements on the theoretical main point of PWS by one of its founders, cf. the Concluding Unscientific Postscript in Kripke (2011, 377-378). 
the admission of singular terms that may not have a referent. In such systems, some of the usual rules of derivation are restricted; for instance, we cannot derive $\exists x \mathrm{~F}(x)$ from $\mathrm{F}(\mathrm{c})$. The other alternative is to renounce to the rule of necessitation; which establishes that if $A$ is a theorem, then so too is $\square A$.

Both options have a negative consequence, highlighted by Williamson: the logical complexity is increased; there is a significant loss of simplicity. I am going to assume that accepting free logic (rather than dropping necessitation) is the best choice for the contingentist. Williamson presents a detailed enumeration of the problems encountered by free logic, related to the fact that it would be less simple than classical, unfree logic. "In practice, the axiomatizations of such 'free' modal logics are often quite complicated" (Williamson 2013, ch. 2, note 11); "whether or not contingentists retain the rule of necessitation, their system overall has aspects of a free modal logic. This is an early indication that contingentism has costs in logical complexity" (ch. 2, p. 16). ${ }^{5}$

My reply to this criticism is dual: it combines some moderate scepticism (or agnosticism) about the alleged fact that free logic is objectively more complex than classical un-free logic with minimizing in a certain way the relevance of such a difference in simplicity.

How objective (mind-independent, not related to human capacities) would the supposed fact that free logic is more complex than classical logic be? A Spanish driver could innocently say "Driving on the right is more simple, less complicated, than driving on the left". The little truth there is in her assertion would be close to this: she is used to driving on the right, and — as a consequence-driving on the left would now be more complicated for her than driving on the right. At the other end of the spectrum, we probably think that addition is more simple than quaddition, in a much more objective sense of 'simplicity'. ${ }^{6}$ It seems plausible that any rational being (not only any human being) would "feel" and think (if equipped with cognitive capacities to represent and understand the issue) that addition is more simple than quaddition. If classical logic were more simple than free logic in some similar sense (and degree) to the way in which addition is more simple than quaddition that would constitute very strong evidence against free logic. But, where in that broad spectrum (with the case of the driver at one end and addition/quaddition at the other) is the case of free/classical logic located? How complex or complicated would it be (or would it be for us) to engage in systems of free logic? Someone can say that there is a very clear sense in which free logic is more complex than classical logic: the axioms and/or inference rules and the derivations are more complex. But the question remains: how objective is such greater complexity?

${ }^{5}$ Similar considerations of simplicity also appear in later chapters. For instance, with regards to the discussion of our previous section, we find: "Although contingentists can tell some sort of representational story to connect the model theory with the intended modal interpretation, their story is too indirect to make the model theory much more than a complicated digression. By contrast, necessitists can connect the model theory to the intended interpretation directly" (Williamson 2013, section 3.6).

${ }^{6}$ Quaddition can be defined as follows: for any natural numbers, $n, m$, if $n$ or $m$ is greater than the greater number that has never been added, then $n$ quus $m$ is 7; otherwise, $n$ quus $m$ is the same as $n$ plus $m$. 
Most of us with some explicit knowledge of logic have learned classical un-free logic, and have little or no expertise in free logic. Some of the complications of free logic will stem from this (maybe almost universal but nonetheless) biographical fact. Williamson's case cannot depend solely on that complexity (stemmed from facts about what we learn first). Maybe (I do not know if there is a known answer to this) free logic is objectively more complex for any human being, due to traits of human cognitive architecture which nonetheless cannot be extrapolated to all possible rational thinkers. If that were so, it would favour Williamson's case; although not very much. The central concept of logic is the concept of logical consequence. This notion is abstracted from the notion of rational argumentation; rational argumentation alone; which is not necessarily restricted to possible contingencies linked to buman rational argumentation (even though, of course, the paradigmatic known cases of rational argumentation involve human beings).

On the other hand, simplicity is just one of the criteria that are to be taken in consideration; it cannot be as decisive as Williamson's claims seem to suggest. (Obviously, the scepticism expressed in the previous paragraphs also contributes to minimizing the importance that we should attach to a parameter that is so difficult to determine.) It is just one factor to be considered.

There is an additional, ad hominem, reason to resist the appeal to simplicity. It seems to me that considerations of simplicity (in the context of addressing the question: What is the right logic?) would have more strength if the underlying philosophical conception of logic were more classical, less realist than the conception defended by Williamson. I would say that the more objective (about the world itself; mindindependent) a discipline is (or the subject matter of that discipline is), the less weight considerations of simplicity have. (I am not claiming that in the most objective theoretical disciplines simplicity is of no importance; in fact, I reject that claim.) But, precisely, Williamson has worked out a view according to which logic is seen as a theory of very general traits of the world, close to the idea of logic as ultra-physics or ultrametaphysics, or even not clearly different from general metaphysics. (Cf., for instance, Section 3.7 of Williamson 2013.) In this respect, given such an objectivist view of logic, simplicity counts for even less than what it would in more classical (conceptual, or analytical) views of the nature of logic.

The conclusion I want to extract from the discussion in this and the preceding section is that the strong double evidence against BF1 (based on pre-theoretical intuitions and ontological parsimony) is not overridden by the evidence invoked by Williamson in his defence of Nec1. Adopting free logic (which has received independent support in the literature, unrelated to any ad hoc move aimed at saving our contingentist intuitions) seems to be less revisionist than postulating Williamson's non-concrete but possibly concrete entities.

\section{Higher-order necessitism}

In this section, I maintain that the evidence we could have against Nec2, necessitism about properties, is weaker by far than the evidence we have against Nec1, necessitism about individuals, described in Section 2. Relevant data favouring Nec2 could, there- 
fore, be decisive in tipping the balance. In my view, the evidence for Nec2 provided by Williamson (2010; 2013, ch. 6) seems to be decisive enough. I am inclined to accept that necessarily every property necessarily exists.

As Williamson explicitly proposes, the properties we are talking about in a formula like Nec2

(Nec2) $\quad \square \forall X \square \exists Y(X=Y)$

have to be properties in a very broad sense of the concept property. They are the appropriate values that second-order variables in our language can take (cf. Williamson 2013, ch. 5). So, to a certain extent, they are, more similar to set-like entities than-for instance-to entities with the ontological weight that many philosophers attribute to universals conceived as ultimately being responsible for the causal powers of things. ${ }^{7}$

It is important to be aware that (in the context of the discussion in this paper) the debate about existence or non-existence of some alleged properties-the debate about whether Nec2 is true or false-is concerned with this broad sense of properties. Having such a broad sense in mind, it is not so hard to accept the ontological proliferation of entities derived from Nec2. For example, a classical point that is disputed is the status of non-instantiated properties. Some philosophers claim that having instances is a necessary requirement for a property to exist. Properties that are conceived of with that requirement are sometimes called immanent. According to this view, there could be some properties that actually do not exist: properties instantiated in other possible worlds but without instances in the actual world. If properties are appropriate values for second-order variables, then we must accept the existence of properties corresponding to predicates such as: $x$ is a buman who measures more than 1,5 metres tall but less than 1,9 metres. (Some other views on properties could sustain that this is too specific, or too conjunctive, or not natural enough, or not basic enough, to be a property.) Now, let $r$ and $q$ be rational numbers greater than 1,5 but smaller that 1,9 such that the alleged property $\mathrm{F}$, corresponding to the predicate $x$ is a buman who measures more than $r$ metres tall but less than $q$ metres, has no actual instances. It is very natural to think that $\mathrm{F}$ is instantiated in other possible worlds and it is just by luck that it lacks instances in the actual world. A philosopher who thinks that properties are immanent (they only exist if instantiated) and accepts the existence of millions of properties corresponding to predicates of the form $x$ is a human who measures more than $n$ metres tall but less than $m$ metres should nevertheless reject the actual existence of property F. I do not think that our pre-theoretical intuitions clearly favour this immanentist philosopher. But this is a typical case that could be adduced to oppose Nec2; a case based on the idea that properties only exist in possible worlds where they are instantiated.

In general, I do not think that we have strong pre-theoretical intuitions for or against Nec2. If my impression is right, then an important source of evidence for contingentism about individuals is completely (or almost completely) absent in the parallel

\footnotetext{
${ }^{7}$ I am sympathetic myself to such an ontologically weighty view about universals (cf. ch. 4 of Pérez Otero 1999). I just say that this sense of property is not exactly the sense which is relevant when evaluating $\mathrm{Nec} 2$, especially with regards to Williamson's data for Nec2 that I am going to mention.
} 
case regarding contingentism about properties. Therefore, on issues regarding the ontological status of properties, theoretical inquiry has to play a more important role.

The other source of evidence for contingentism about individuals invoked in Section 2 was ontological parsimony. If $\mathrm{Nec} 1$ was accompanied by the postulation of a new category of beings (such as Williamson's non-concrete but possibly concrete entities), then the result was uneconomical, in two ways: it proposes the actual existence of a lot of new things (things we did not think existed); and worse, it also proposes the actual existence of a new ontological category. $\mathrm{Nec} 2$ would only violate ontological parsimony in the first sense, if at all. If the opposition to Nec 2 comes with a commitment to an immanentist view of properties, then Nec2 certainly involves the existence of a lot of new properties, such as F, but each of which belongs to the same kind as some old ones postulated by second-order contingentism (F, for example, is very similar to the properties-accepted by the immanentist—corresponding to predicates with the form of $x$ is a buman who measures more than $n$ metres tall but less than $m$ metres). If $\mathrm{Nec} 2$ is rejected on different grounds (that are compatible with non-immanent properties), we should wait and see what the other motivation is, in order to appraise what the ontological cost of Nec2 amounts to.

Now, let us have a quick look at the arguments employed by Williamson to defend Nec2. The basic idea is the following. There are some important desiderata related to the expressive capacities of higher-order languages that can only be satisfied if Nec2 is true (they require, in fact, the truth of general higher-order necessitism, from which Nec2 follows). For instance, one of the desiderata is the need (in set theory) to avail ourselves of principles of comprehension such as (this is a version restricted to monadic second-order variables): $\exists X \square \forall x(X(x) \leftrightarrow A(X))$.

Williamson examines with detail and criticizes the options open to the higher-order contingentist to meet such desiderata without Nec2 (cf. Williamson 2010; 2013, Sections 6.1, 6.3 and 6.4). Here I cannot go into the discussion of these issues, as that would be a matter for another entire paper, at least. As I advanced above, I tend to accept Williamson's position on this particular question. His argument seems to me strong enough to override the previous evidence we had for higher-order contingentism (as far as I can see what that previous evidence may be). I think that any former agnostic view about $\mathrm{Nec} 2$ (or even a view slightly inclined against Nec2) should be revised to (more or less confident) acceptance of Nec2 in the light of the evidence provided by Williamson.

My preferred position about the contingentism/necessitism debate is, therefore, to reject necessitism about individuals (Nec1) and to tentatively accept higher-order necessitism, of which necessitism about properties (Nec2) is a particular case.

\section{Minimalist first-order contingentism}

Williamson argues against the hybrid view (Nec2 without Nec1) independently of his other objections to Nec1. He offers an argument aimed to show that there is an important problem in the heterogeneity postulated by the hybrid view. Let us say that the haecceity of an individual, $y$, is the property of being necessarily identical to $y$, in the sense predicated of $\mathrm{X}$ in the formula: $\square \forall x(\mathrm{X} x \leftrightarrow x=y$ ) (so, ' $\mathrm{X}$ is a haecceity of $y$ ' is 
another way to express this formula). Now, once we grant Nec2, we must accept the necessary existence of haecceities of any possible individual. All possible worlds contain the same properties, and-in particular-the same haecceities. Even if $y$ does not exist in possible world $w$, the property corresponding to ' $\mathrm{X}$ is a haecceity of $y$ ' exists in $w$. For instance, the property of being Socrates would also exist in worlds where-for first-order contingentists-Socrates does not exist. The problem is that haecceities are relational properties that seem to be metaphysically dependent on the corresponding individuals. The haecceity of $y$ seems to involve metaphysically $y$. It would seem that $y$ is a constituent of the property. But how then can the property exist if (according to contingentism about individuals) $y$ does not exist? (Cf. Williamson 2013, section 6.2.)

Several answers to the problem are examined and criticized by Williamson. In my view, some versions of two of them have good prospects for being deemed reasonable replies to the objection.

The first one is based on an answer Williamson classifies as minimalist. The ideaas I would have it -is to reject the question as a pseudo-problem, or to reject it simply because it depends on the false assumption that haecceities are metaphysically dependent on singular entities (maybe these are two different answers). Here, once again, it is relevant the fact that when speaking of "properties" we are talking about appropriate values of second-order variables. The impression that the haecceity of $y$ $(\square \forall x(\mathrm{X} x \leftrightarrow x=y))$ metaphysically depends on $y$ would be probably more pressing if we assumed a more substantive view about the nature of properties. The minimalist answer says, in Williamson's own terms: "we need no more explanation of how my haecceity singles me out in my absence than that it is the property that, necessarily, applies to something if it is me and not otherwise" (Williamson 2013, section 6.2).

In reply, he writes:

One danger for minimalist contingentism is that the minimalism leaves the contingentism looking suspiciously ad hoc [...] The onus is on the metaphysician who postulates such logical differences between orders to justify the asymmetry in treatment. Minimalism deprives the contingentist of the resources needed to provide a satisfying justification. [...] The default preference is for a uniform metaphysics, on which being is contingent at all orders or none. (Williamson 2013, sec. 6.2)

This objection has some force, but I do not think that it goes too far. Individuals and properties (of any order) are ontologically as different as two kinds of entities can be. It should not be surprising that they mark a difference with respect to the contingentism/necessitism issue. It is far from clear that the default preference-in this respect—is for a uniform metaphysics. ${ }^{8}$

\footnotetext{
${ }^{8}$ It is fair to say that Williamson takes this kind of counter-reply on the part of the minimalist contingentist into consideration. He claims "even if we grant that metaphysical difference for the sake of argument, [...] it does not really explain the non-contingency of higher-order being" (Sec. 6.2). As I understand the minimalist stance, there would be no need for such an explanation. What Williamson wants to see explained would be a consequence of the conceptually basic difference between individuals and "properties".
} 


\section{Modal metaphysical atomism}

The second answer to the problem that I find sensible is a relational strategy, which naturally leads us to a certain atomist metaphysical hypothesis. Even if a certain knife, $k$, does not exist in world $w$, we can account for the existence of its haecceity in $w$ if $k$ is essentially uniquely related to some other things that exist in $w$. Natural candidates for those other things are certain parts of $k$, for instance its handle and its blade. If $k$ can be essentially uniquely characterized in terms of these and some other constituents, ${ }^{9}$ then the existence of these constituents would suffice for the existence of $k$ 's haecceity, whether or not $k$ exists. Of course, this relational strategy cannot stop at the handle and the blade of the knife. Contingentists about individuals will claim that handle and blade are contingent beings too. As Williamson clearly remarks: "To solve the problem by the relational strategy, the contingentist requires this for each individual $i$ necessarily, there are some individuals to which $i$ is essentially uniquely related." (Williamson 2013, section 6.2). The contingent knife $k$ would have essential constituents (in terms of which it could be uniquely characterized and) that are necessary beings. The same happens with any other contingent individual (Socrates, his birthday, the planets, etc.). Let us call such necessary constituents of the contingent individual $z$ metaphysical atoms of $₹$. The individuals typically conceived of as contingent by contingentists are (events and) material objects. It is natural to think that if they have necessary essential constituents, then those constituents are (basic events and) basic microphysical objects. Whatever their ultimate nature, the hypothesis is the following: necessarily, for each individual $z$ there are some individuals to which $z$ is essentially uniquely related and that necessarily exist. ${ }^{10} \mathrm{I}$ call this modal metaphysical atomism. We do not know whether modal metaphysical atomism is true or not. What we have found, however, is this: first-order contingentists who accept higher-order necessitism but are unhappy with the minimalist reply to the problem about haecceities posed by Williamson (and dislike any other response to it) may be inclined to accept modal metaphysical atomism. Granted the other assumptions, they may contemplate the need to solve that problem as indirect but non-negligible evidence for such a speculative metaphysical hypothesis.

Williamson presents four interrelated objections to modal metaphysical atomism (as conceived of in the context of the relational strategy to defend the hybrid view),

(i) The microphysical basic constituents that physics can discern are unpromising candidates for necessary being by contingentist standards, because they could all have not existed.

(ii) There is no good independent evidence for the hypothesis that what tokens of ultimate particles there are is non-contingent.

\footnotetext{
${ }^{9}$ Some events are probably to be included among the other constituents, not just objects. They would contribute to fixing traits of the origin of the knife that are essential to it but which cannot be characterized solely in terms of objects. For a view about how events can be essential to living beings, cf. Sections III.4 and IV.1 of Pérez Otero (1999).

${ }^{10}$ This condition is trivially satisfied by necessary individuals (numbers, for instance, that contingentists can happily accept as non-contingent): they are essentially uniquely related to themselves.
}

Theoria 78 (2013): 393-406 
(iii) The relational strategy is a huge concession to necessitism.

(iv) The relational strategy, in postulating such necessary atoms, tends to undermine the motivation for being contingentist about other individuals:

The natural starting-point for the contingentist's rejection of the necessitist's contingently nonconcrete objects is that they are mere postulates of abstract metaphysical speculation, with no basis in common sense or natural science. The relational strategy for saving haecceities [...] involves just such speculation, and leads to postulating significantly more complicated metaphysical structure beyond the reach of common sense or natural science than necessitism itself requires. (Williamson 2013, section 6.2)

I have accepted point (ii). Among the many remarkable features of Williamson's exposition in his 2013 book, is precisely that it offers elements that-under very different background assumptions from those of Williamson-could be seen as evidence for an old speculative hypothesis for which it is so difficult to gain evidence: modal metaphysical atomism. But we do not have any evidence for (i) either. There is no rationale for the contingentist about individuals to think that all basic microphysical entities must be contingent. ${ }^{11}$

That leads us to points (iii) and (iv). There is no unwanted concession to necessitism if we adopt the relational strategy. (Of course, contingentism about individuals is not fuelled by some general prejudice against necessary objects.) The main motivation for the contingentist's rejection of the necessitist's contingently and temporarily non-concrete objects - at least as I conceive and defend the contingentist stance-is slightly misidentified in point (iv). Williamson is right in this much: metaphysical atoms are mere postulates of abstract metaphysical speculation, with no basis in common sense or natural science, just like his contingently and temporarily non-concrete objects. But contingentists reject Williamson's ontology (contingently and temporarily nonconcrete objects) not because it has no basis in common sense (or natural science), but-to put it in a nutshell-because it goes against common sense (conflicting with pre-theoretical intuitions) and against ontological parsimony, and the evidence offered to override these prima-facie data (the extensive abstract theoretical inquiry developed by Williamson, or other authors) is deemed insufficient. In my view, the entities postulated by modal metaphysical atomism do not violate common sense at all; and their departure from ontological economy is not so radical.

As should be clear by now, modal metaphysical atomism is not the only way to save the hybrid view (contingentism about individuals combined with higher-order necessitism) from the problem about haecceities. Another option is the minimalist response mentioned in the previous section. There are also the other responses examined and rejected by Williamson (which I have not presented here).

Let us assume, however, that modal metaphysical atomism is the best option for contingentists. In the end then, we have two main highly speculative alternative views on modal ontology. There existed Wittgenstein, for instance, that had no children. All

\footnotetext{
${ }^{11}$ It is relevant to mention here the familiar Kripkean caveat about not conflating real (metaphysical) contingency with mere epistemic contingency. Cf. Section IV.3 of my Pérez Otero (1999) for more on the necessary character of basic entities and laws of nature.
} 
parts agree on that. Now, each option postulates new actual entities, related to Wittgenstein in some ways, to account for certain facts:

(a) Our actual world contains contingently non-concrete objects that can be children of Wittgenstein. They are concrete children of Wittgenstein only in some possible worlds. But they are necessary beings, existing in all possible worlds, just like Wittgenstein.

(b) Our actual world contains metaphysical atoms of Wittgenstein. They are necessary beings, existing in all possible worlds. So, they also exist in possible worlds where they are not arranged to constitute Wittgenstein (where, therefore, Wittgenstein doesn't exist). In the same way, our actual world contains metaphysical atoms that in some other possible worlds are arranged to constitute a certain child of Wittgenstein.

It is the impressive work of conceptual clarification and precision developed in Williamson's texts on modal logic and metaphysics that have brought us to this dilemma between (a) and (b). I have suggested that the second horn is better supported by the overall evidence.

\section{REFERENCES}

Chihara, Charles. 1998. The Worlds of Possibility: Modal Realism and the Semantics of Modal Logic. Oxford: Oxford University Press.

Kripke, Saul. 2011. A Puzzle about Time and Thought. In S. Kripke Philosophical Troubles. Collected Papers, Vol. 1, 373-379. Oxford: Oxford University Press.

Linsky, Bernard, and Edward Zalta. 1994. In defense of the simplest quantified modal logic". In Philosophical Perspectives 8: Logic and Language, ed. J. Tomberlin. Atascadero, Cal.: Ridgeview.

Marcus, Ruth Barcan. 1962. Interpreting Quantification. Inquiry 5: 252-259.

Menzel,Chris.1990. Actualism, ontological commitment, and possible world semantics. Synthese 85:355-389.

Pérez Otero, Manuel. 1996. Verdad necesaria versus teorema de lógica modal. Theoria 11: 185-201.

—. 1999. Conceptos modales e identidad. Barcelona: Edicions Universitat de Barcelona.

—. 2009. El estatus ontológico de los mundos posibles. Crítica 41: 69-96.

—. 2010. Possible Worlds: Structure and Stuff. Philosophical Papers 39: 209-237.

Rosen, Gideon. 1990. Modal fictionalism. Mind 99: 327-354.

Williamson, Timothy. 1998. Bare Possibilia. Erkenntnis 48: 257-273.

—. 2000. The Necessary Framework of Objects. Topoi 19: 201-208.

- 2002. Necessary Existents. In Logic, Thought and Language, ed. A. O'Hear, 233-251. Cambridge: Cambridge University Press.

-. 2010. Barcan Formulas in Second-Order Modal Logic. In Themes from Barcan Marcus, ed. M. Frauchiger and W.K. Essler, 1-39, Lauener Library of Analytical Philosophy, vol. 3.

—. 2013. Modal Logic as Metaphysics. Oxford: Oxford University Press.

Manuel Pérez Otero (PhD in Philosophy, 1996) is Senior Lecturer at the Department of Logic, History and Philosophy of Science of the University of Barcelona, and member of LOGOS (Research Group in Logic, Language and Cognition) since it was founded. His main research areas are epistemology, philosophy of language, philosophical logic and metaphysics. On these topics, he has published several books (the most recent one is Esbozo de la filosofía de Kripke, 2006), as well as articles in journals like Crítica, Dialectica, Grazer Philosophische Studien, History and Philosophy of Logic, Philosophical Studies, Philosophical Papers, Philosophy and Phenomenological Research and Synthese.

AdDREss: Departamento de Lógica, Historia y Filosofía de la Ciencia, Facultad de Filosofía, Universidad de Barcelona, c/Montalegre 6, 08001 Barcelona, Spain. Email: perez.otero@ub.edu 